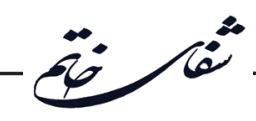

\title{
Effects of Iron on the Neuronal Degeneration of the L4 Dorsal Root Ganglion in an Animal Model of Sciatic Nerve Transection
}

Somaye Mohammadi Abisofla, Morteza Behnam Rassouli, Maryam Mousavinezhad Moghaddam, Naser Mahdavi Shahri

Peripheral Nerve Regeneration Research Lab, Department of Biology, Faculty of Sciences, Ferdowsi University of Mashhad, Mashhad, Iran

Article Info:

Received: 29 Nov 2017

Revised: 12 Apr 2018

\section{A BSTRA CT}

Introduction: Iron is an essential and potentially toxic metal in the mammalian body. In the present study, the effects of Ferrous Sulphate as an exogenous iron on the neuronal degeneration induced by unilateral sciatic nerve transection (SNT) in L4 dorsal root ganglion (L4-DRG) have been investigated in rats. Materials and Methods: Twenty-four male Wistar rat were divided into 4 groups $(n=6)$; control (intact), SNT+ Salin, SNT+ iron (5.6 $\mathrm{mg} / \mathrm{kg}$; i.p), and sham. Treatment was started 1 hour after injury and continued for 7 days following the injury. The L4-DRG were dissected out, fixed (formalin 10\%) and then processed for paraffin embedding 3 weeks after injury. Serial sections of L4-DRGs were prepared, s tained (H\&E and Toluidine blue) and examined microscopically. The mean volume of L4DRG was estimated using Cavalieri principle and neuron count was done by a stereological approach (Disector method). Results: The mean number of neurons in SNT and SNT+ iron groups were significantly decreased compared to the control group. In addition, the mean DRG volume in SNT+iron group was significantly lower than control group. Conclusion: Treatment with iron seems to exacerbate the neuronal death induced by SNT in rats.

Key words:

1. Iron

2. Sciatic Nerve

3. Rats

*Corresponding Author: Morteza Behnam Rassouli

E-mail:behnam@ferdowsi.um.ac.ir 


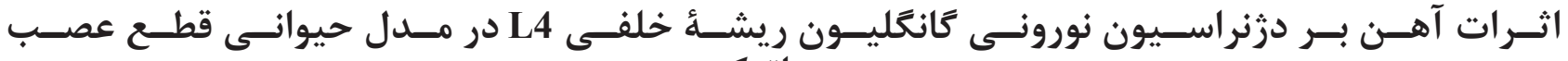
ســـاتيكى

سميه محمدى آبىسفلى، مر تضى بهنام رسولى"، مريم موسوى نزاد مقدم، ناصر مهدوى شهرى

آزمايشكاه تحقيقاتى ترميم اعصاب محيطى، كروه زيست شناسى، دانشكده علوم، دانشكاه فردوسى مشهد، مشهد، ايران

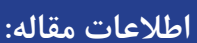

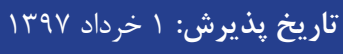

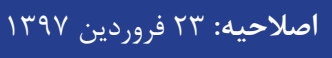

تاريخ دريافت: 1 آذر عهبا

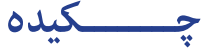

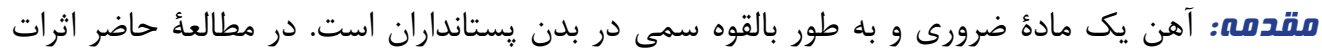

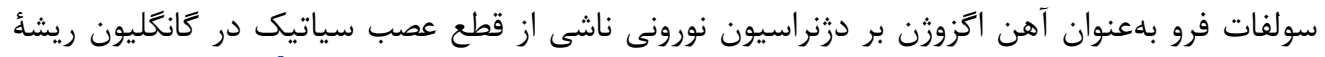

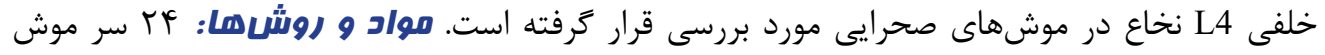

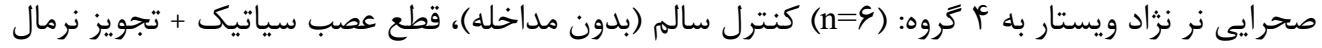

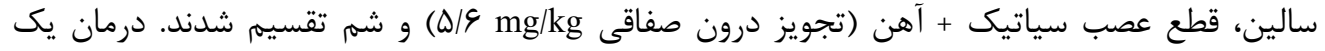

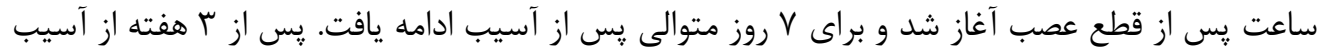

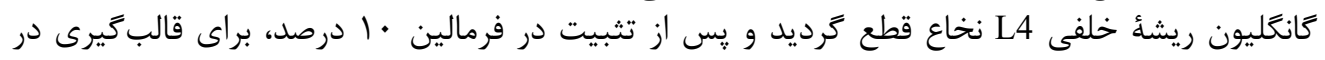

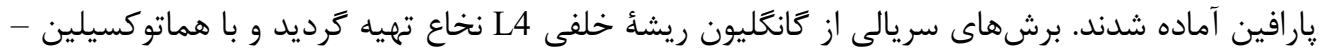

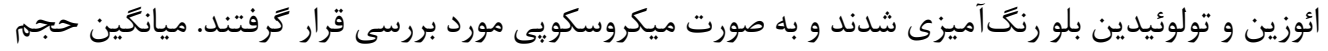

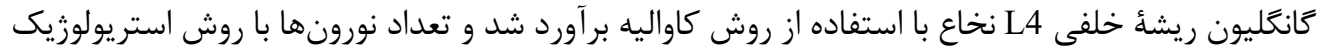

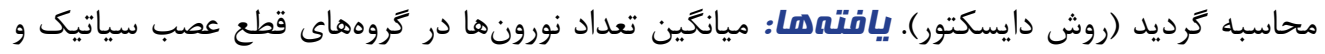

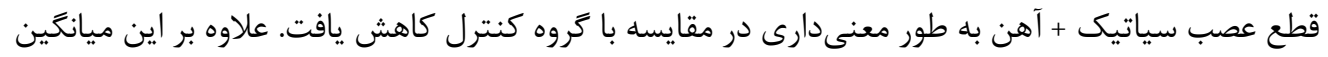

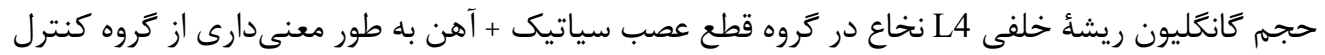

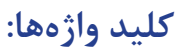

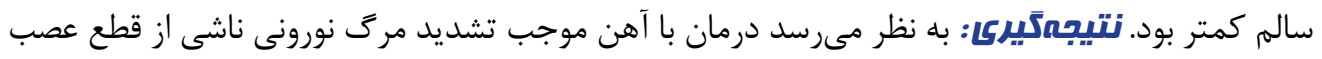

آب آهن

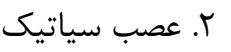

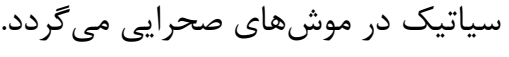

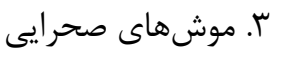




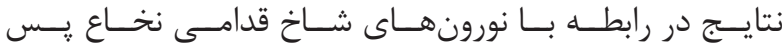

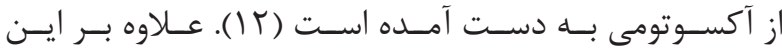

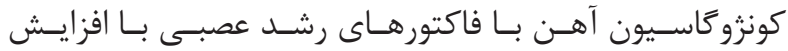

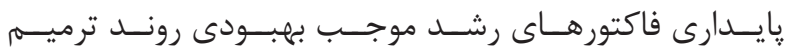

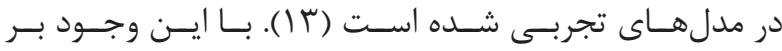

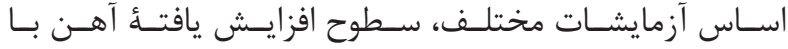

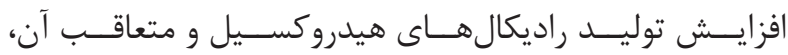

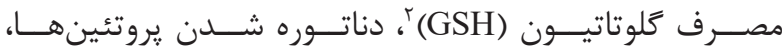

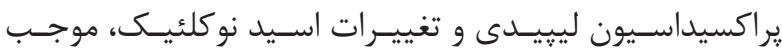

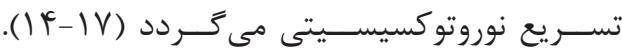

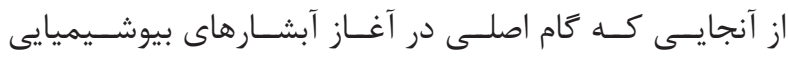

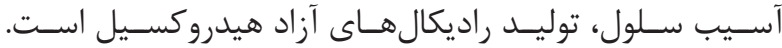

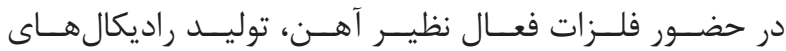

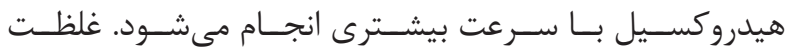

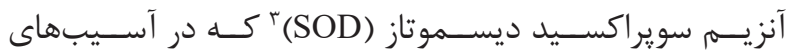

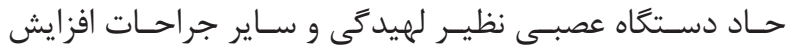

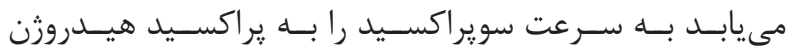

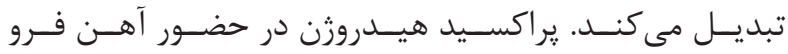

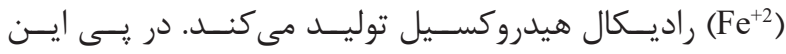

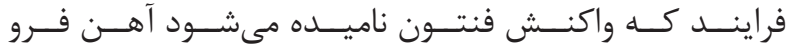

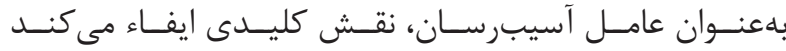

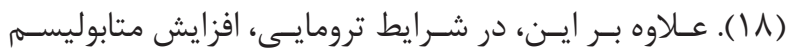

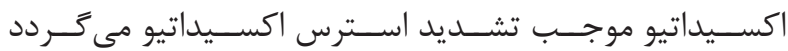

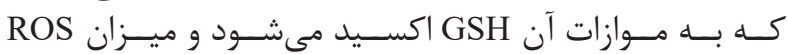

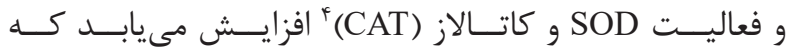

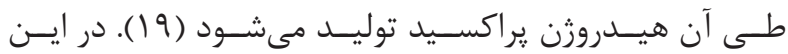

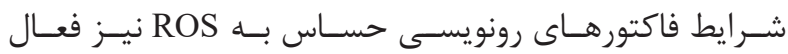

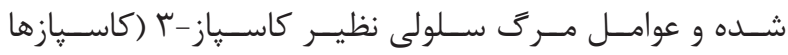

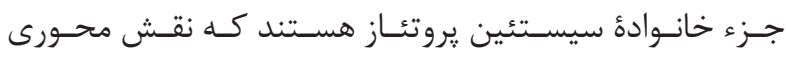

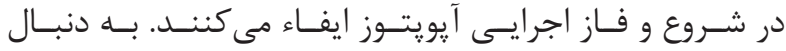

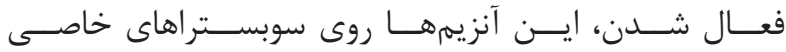

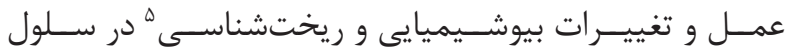

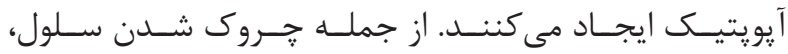

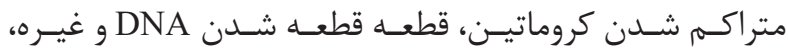

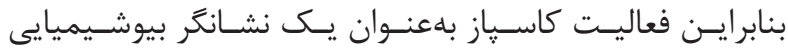

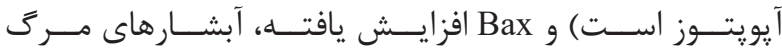

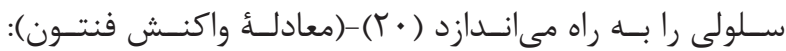

$\mathrm{H} 2 \mathrm{O} 2+\mathrm{Fe} 2+\rightarrow \mathrm{OH}-+\cdot \mathrm{OH}+\mathrm{Fe} 3+$

در واقـع يكسى از قدرتمندتريـن عوامـل دخيـل در آسـيبهاى

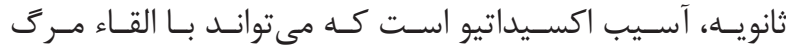

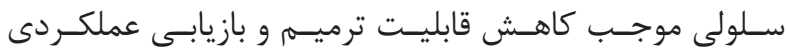

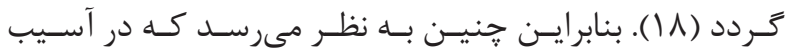

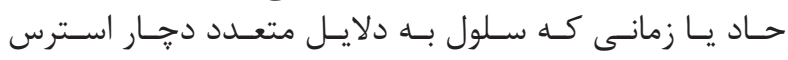

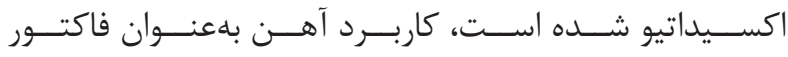

${ }^{1}$ Nerve growth factor

${ }^{2}$ Glutathione

${ }^{3}$ Superoxide dismutase

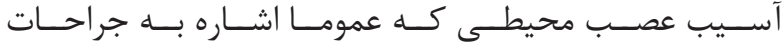

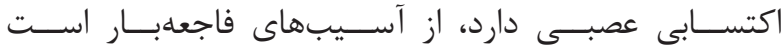

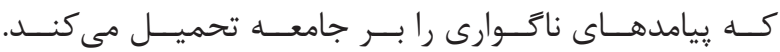

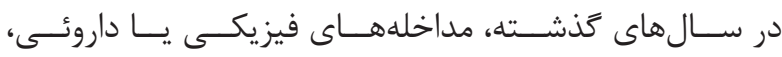

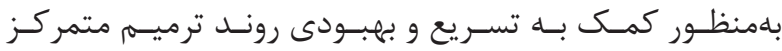

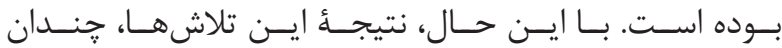

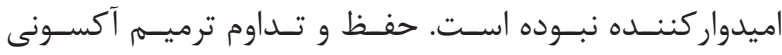

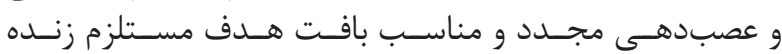

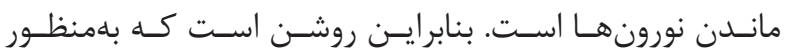

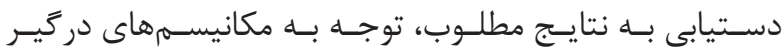

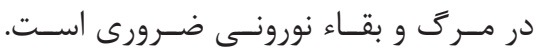

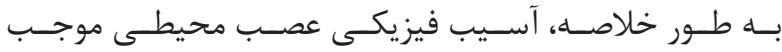

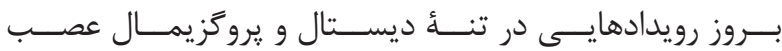

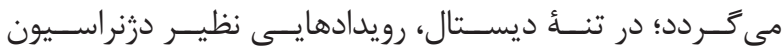

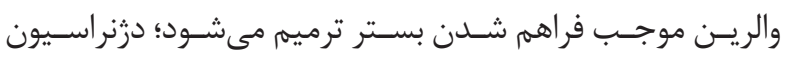

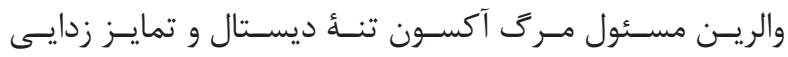

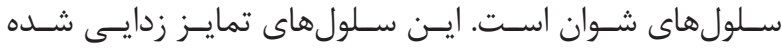

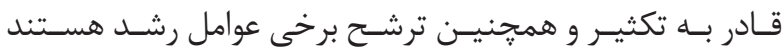

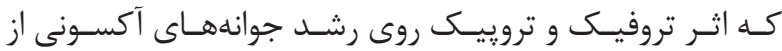

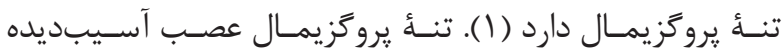

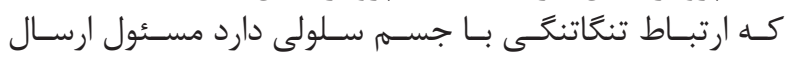

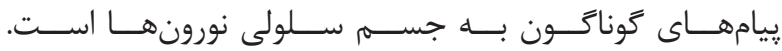

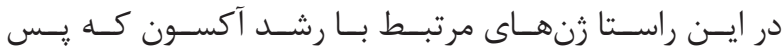

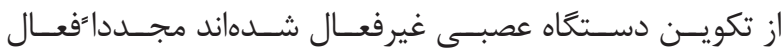

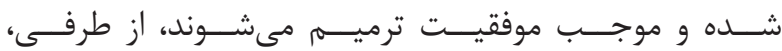

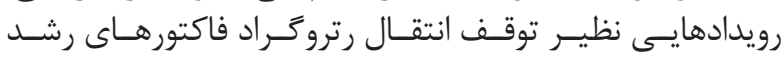

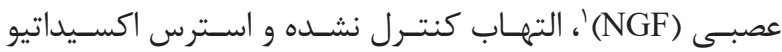

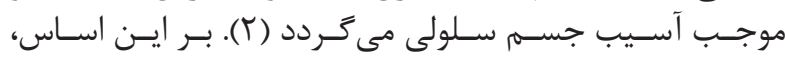

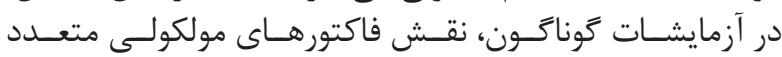

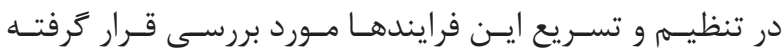

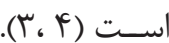

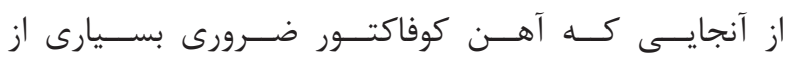

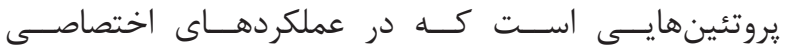

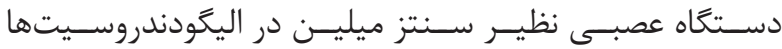

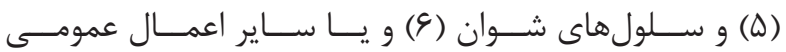

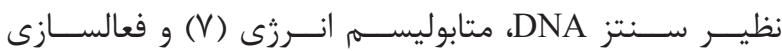

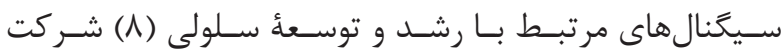

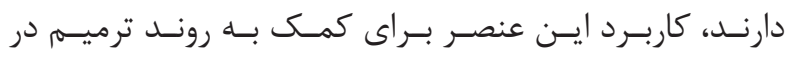

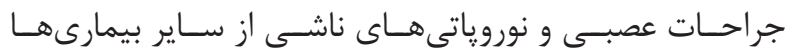

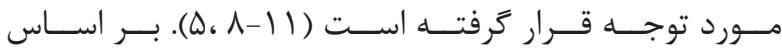

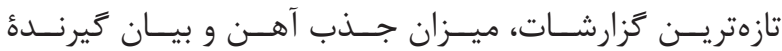

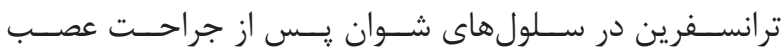

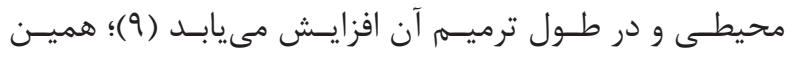

${ }^{4}$ Catalase

${ }^{5}$ Morphology 


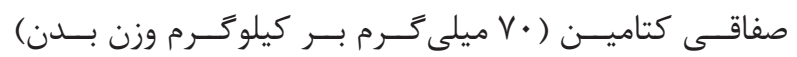

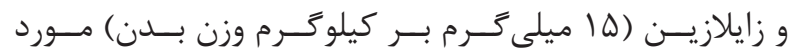

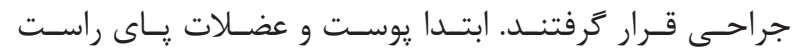

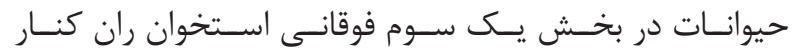

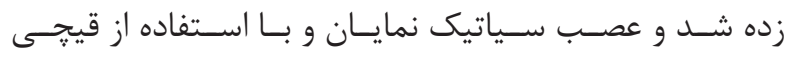

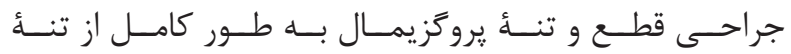

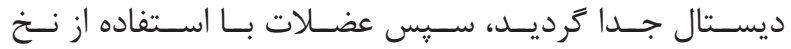

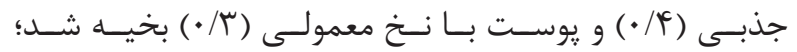

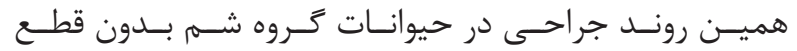

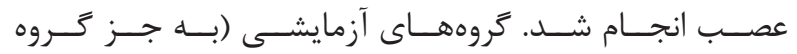

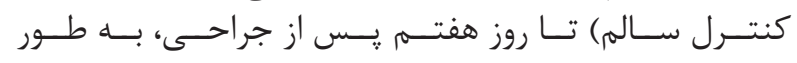

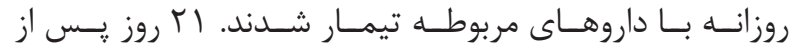

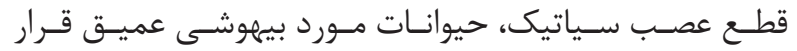

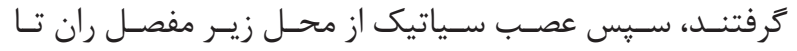

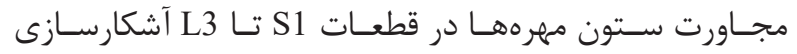

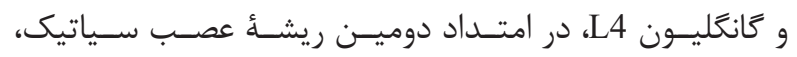

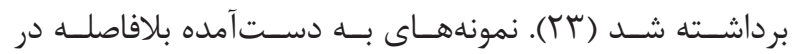

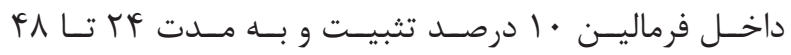

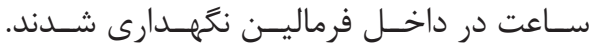

بافت شناسى

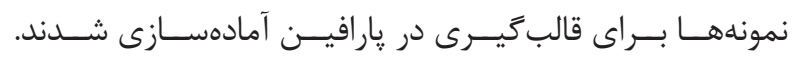

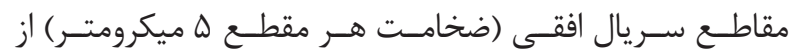

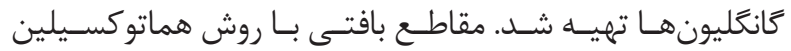

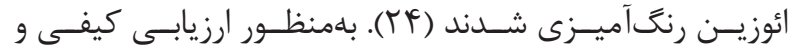

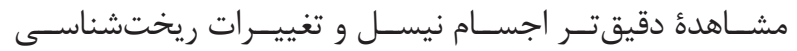

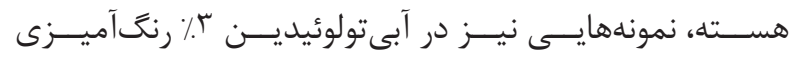

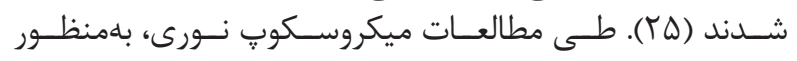

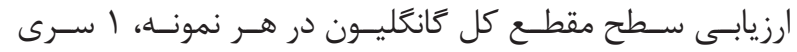

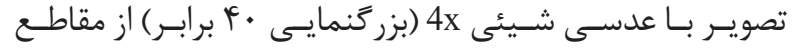

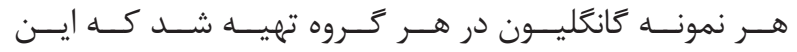

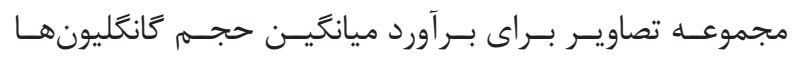

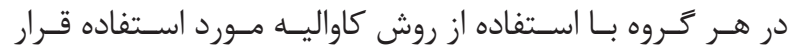

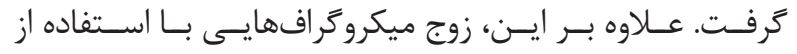

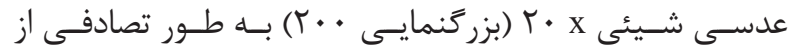

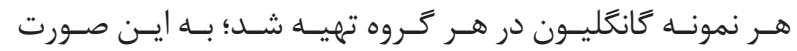

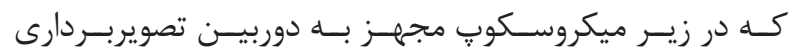

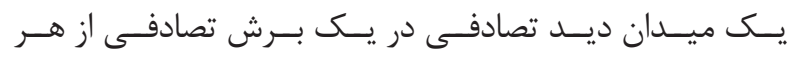

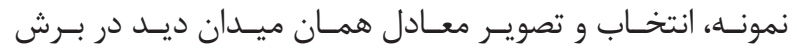

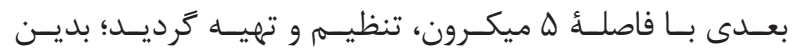

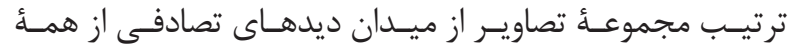

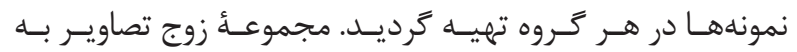

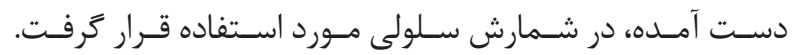

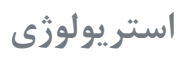

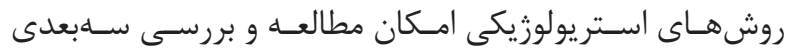

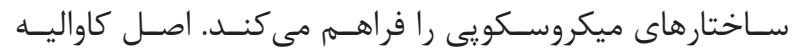

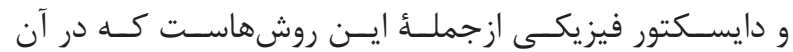

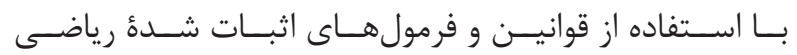

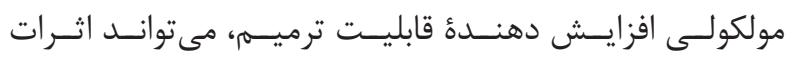

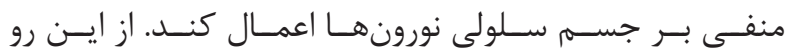

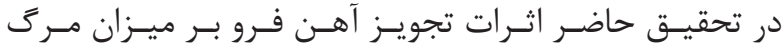

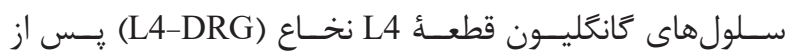

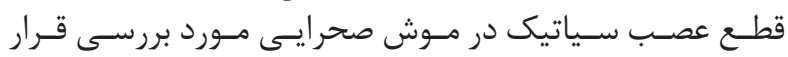

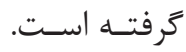

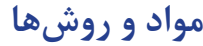

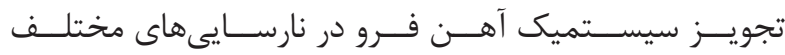

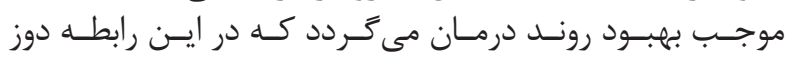

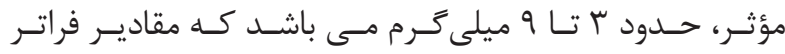

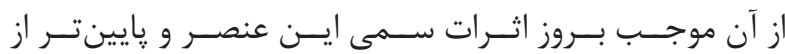

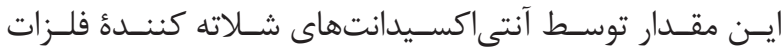

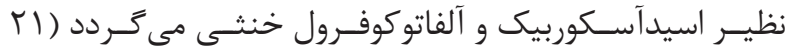

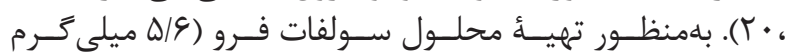

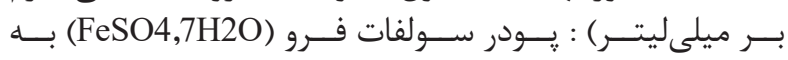

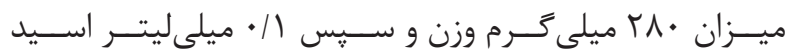

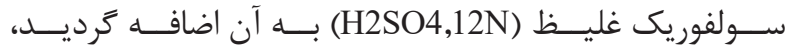

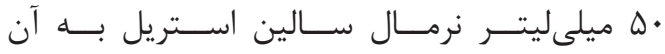

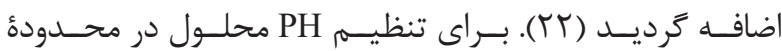

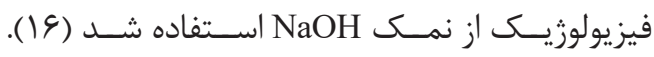

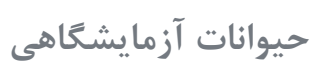

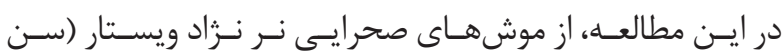

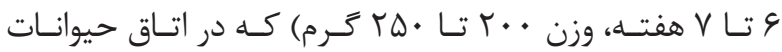

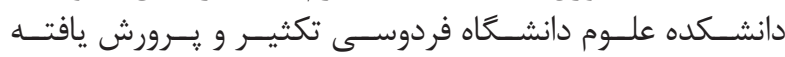

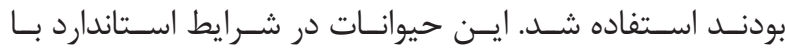

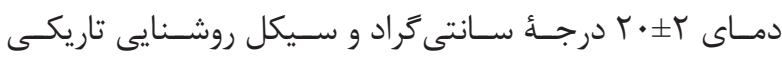

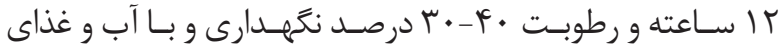

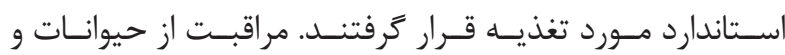

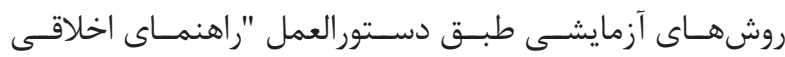

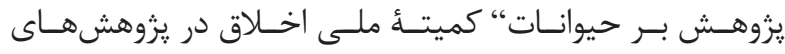

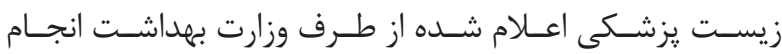

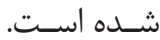

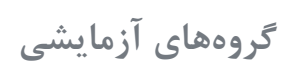

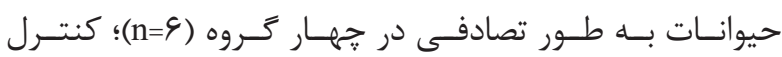

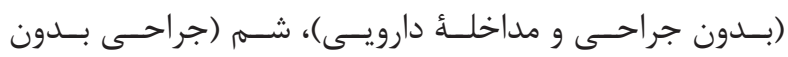

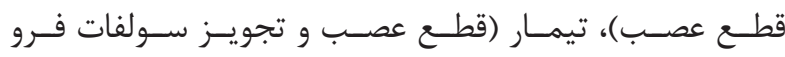

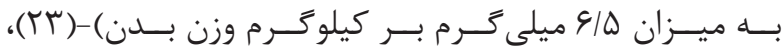

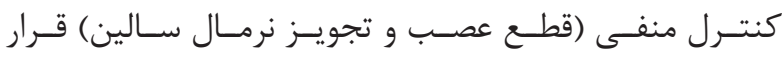

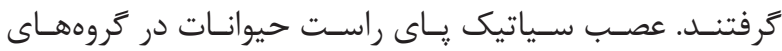

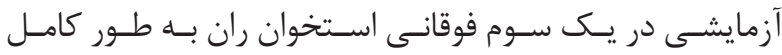

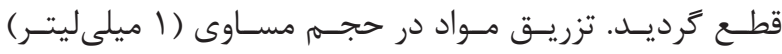

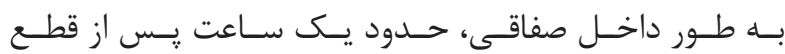

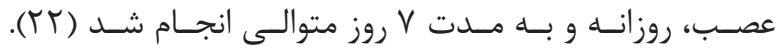
جراحى حيوانـات يـس از بيهوشـى كامـل بــهـ وســيلة تزريـق داخـلـ 


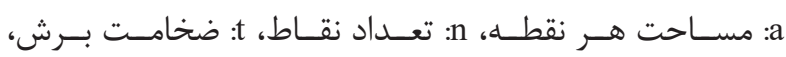

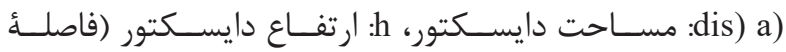

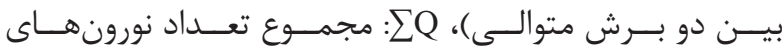

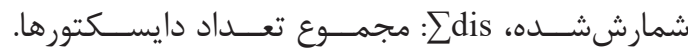
تجزيه و تحليل آمارى

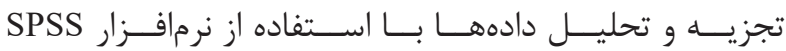

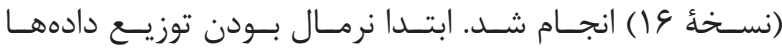

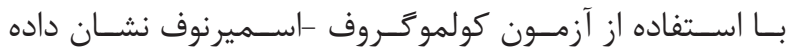

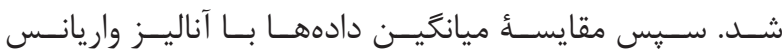
يكىطرفـه (ANOVA) و آزمــون تعقيبـى Tukey انجــام شــد.

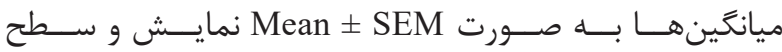

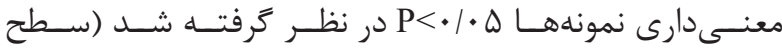

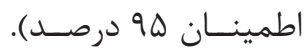

يافته ها

ويثز گى هـاى ريختشناسـى طبيعـى L4-DRGs و تغييــرات

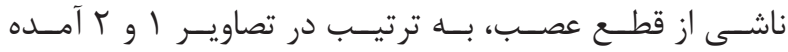

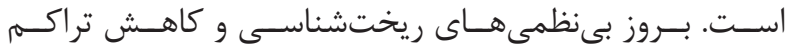

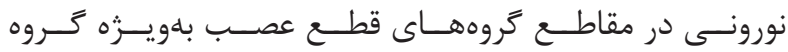

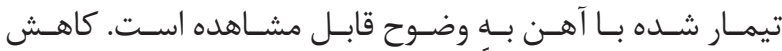

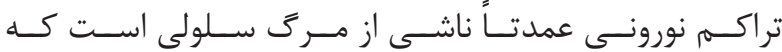

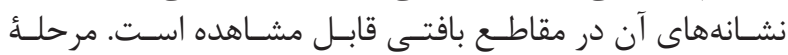

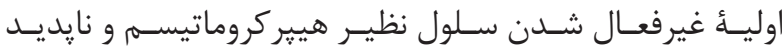

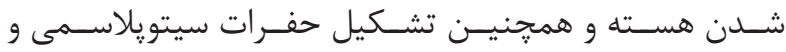

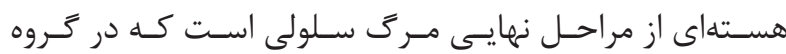

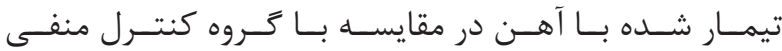

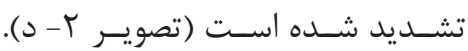

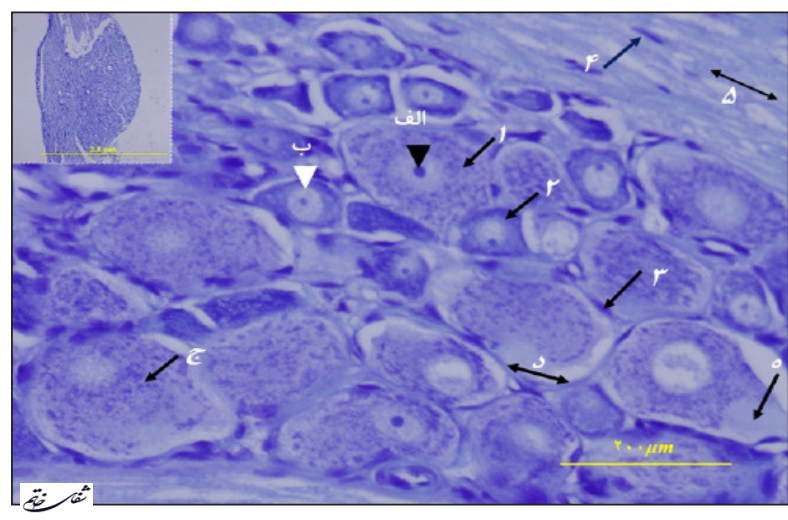

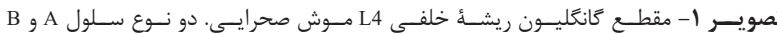

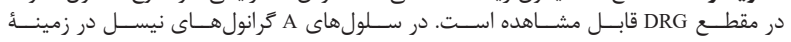

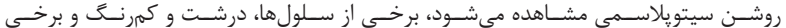

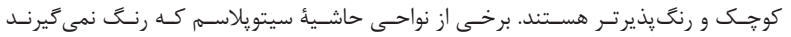

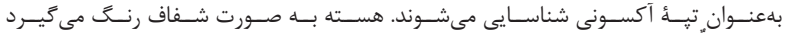

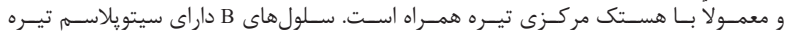

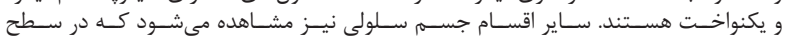

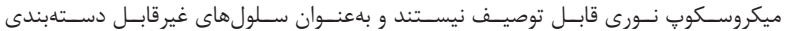

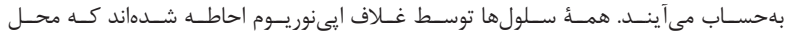

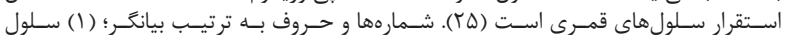

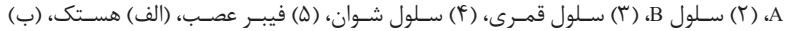

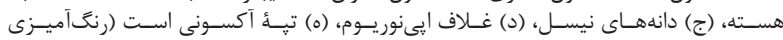

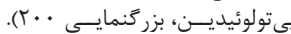

مى تـــوان ارزيابـى و بـــــآورد دقيــق از حجـــم و تراكــم ذرات

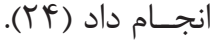

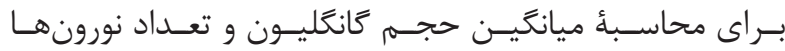

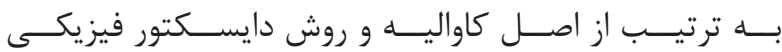

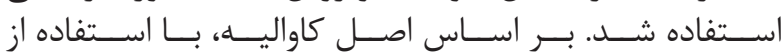

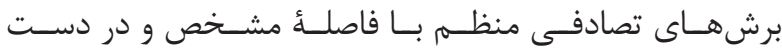

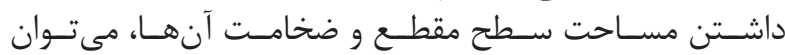

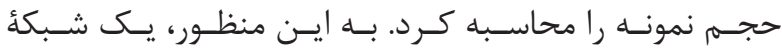

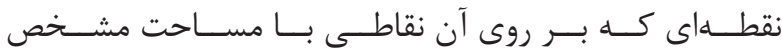

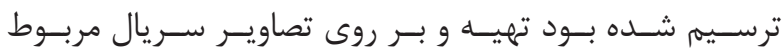

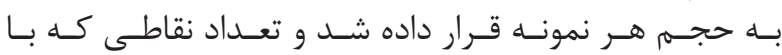

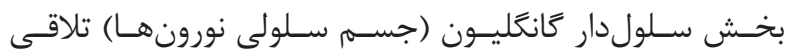

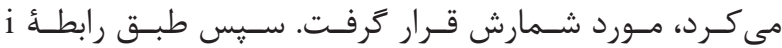

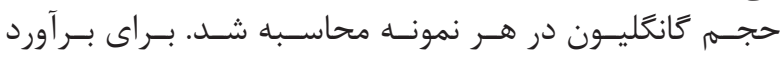

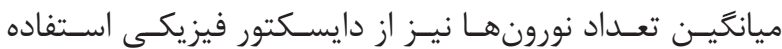

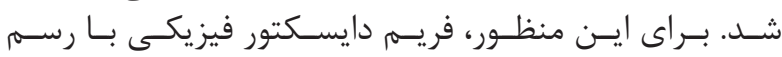

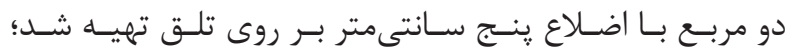

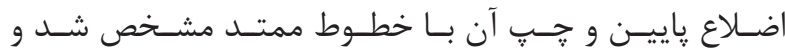

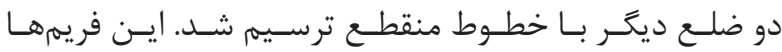

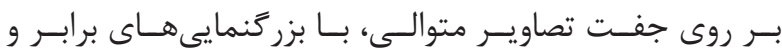

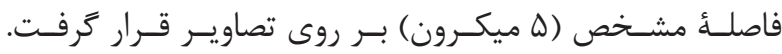

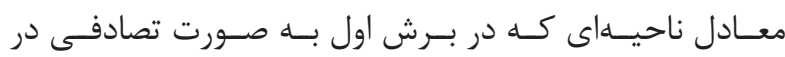

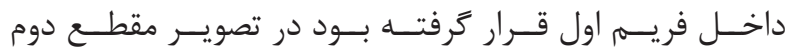

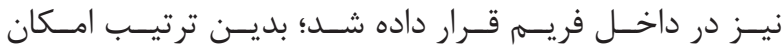

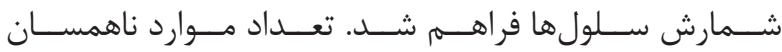

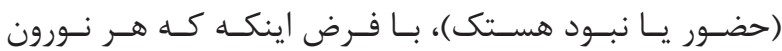

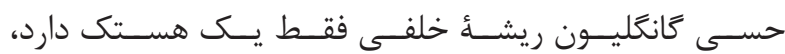

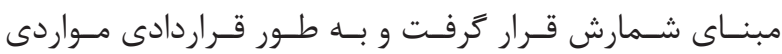

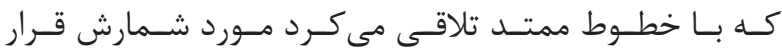

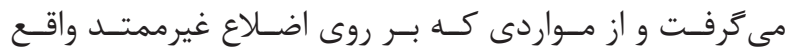

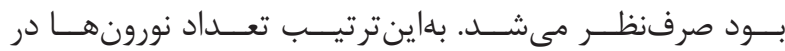

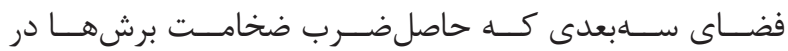

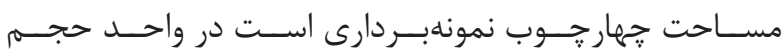

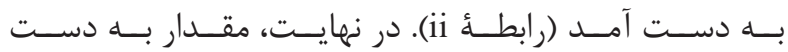

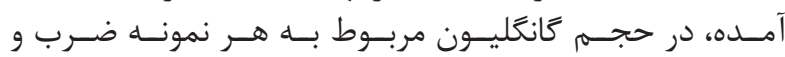

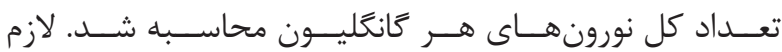

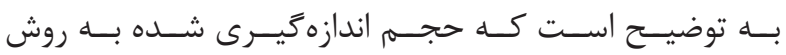

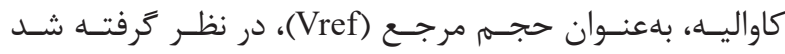

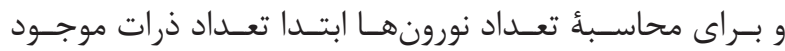

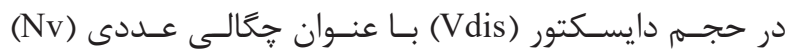

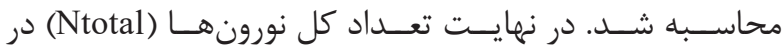

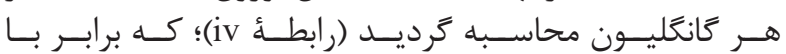

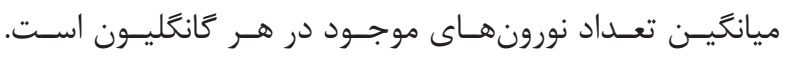

$$
\begin{array}{cl}
\text { i. } & \text { Vref }=a \times n \times t \\
\text { ii. } & \text { Vdis }=a(\text { dis }) \times \mathrm{h} \\
\text { iii. } & N v=\frac{\sum Q}{\sum \text { dis } \times \text { Vdis }} \\
\text { iv. } & \text { Ntotal }=N v \times \text { Vref }
\end{array}
$$




\section{بحث و نتيجه كَيرى}

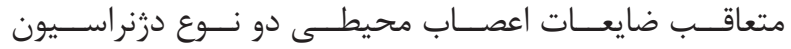

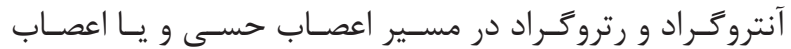

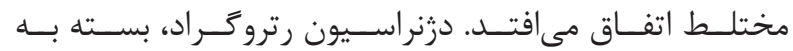

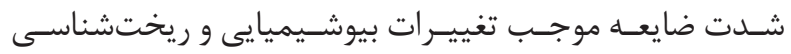

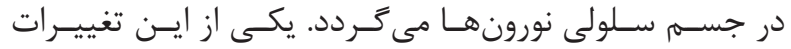

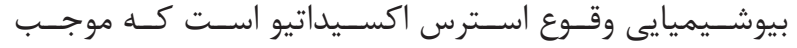

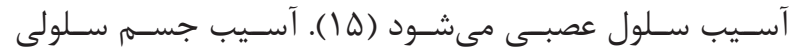

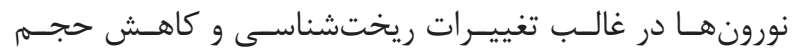

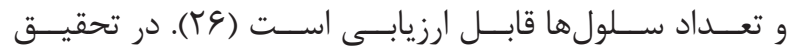

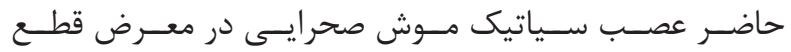

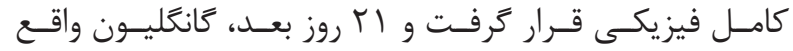

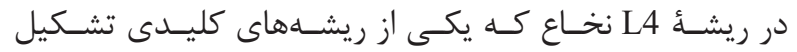

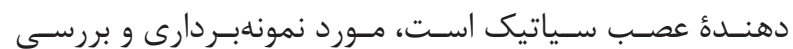

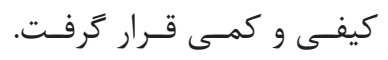

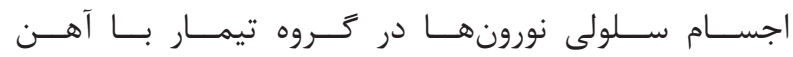

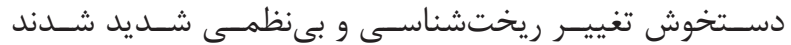

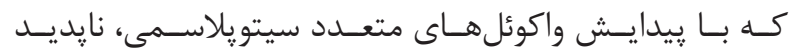

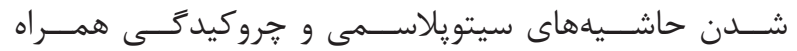

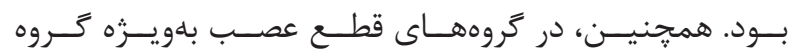

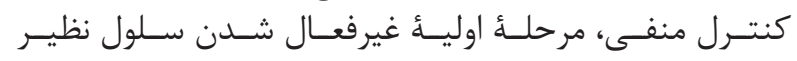

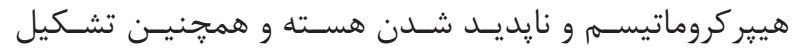

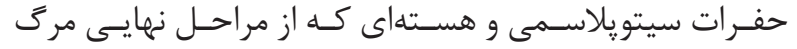

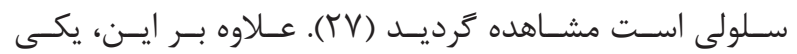

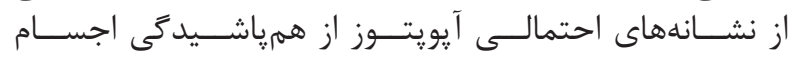

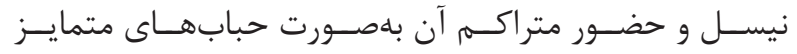

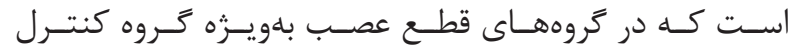

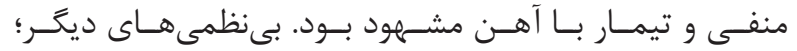

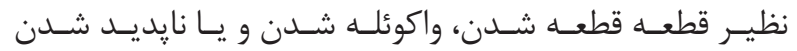

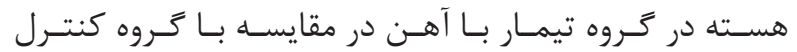

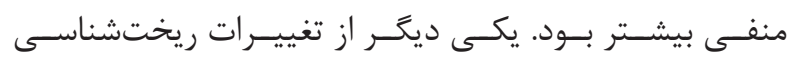

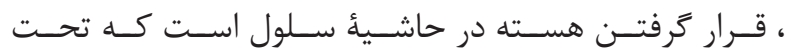

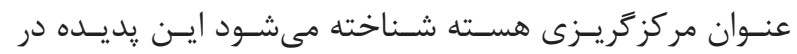

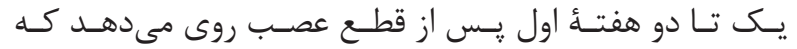

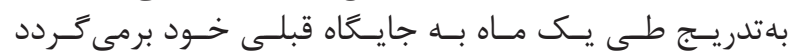

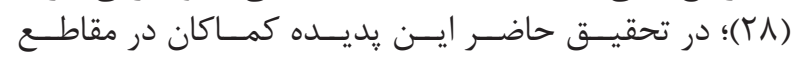

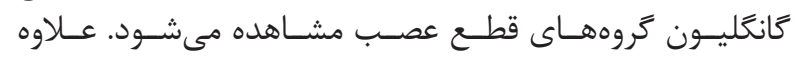

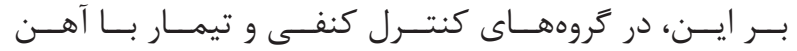

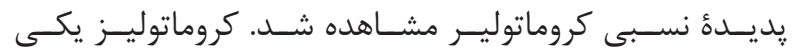

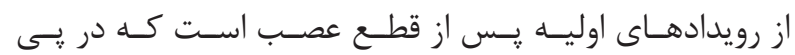

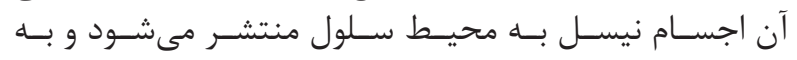

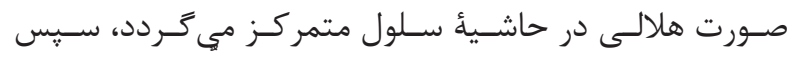

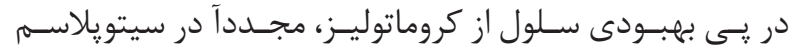

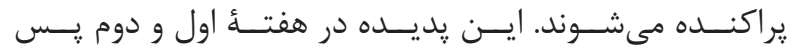

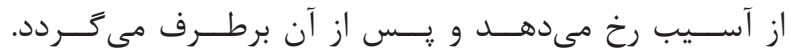

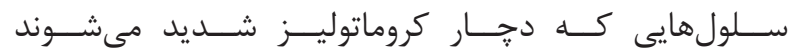

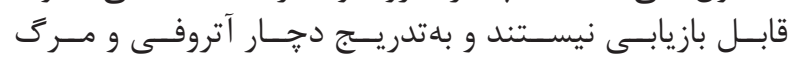
مى شـــوند (rV) - (T).

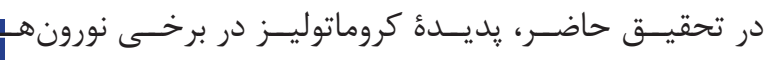




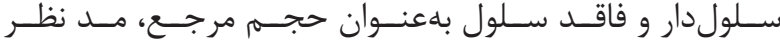

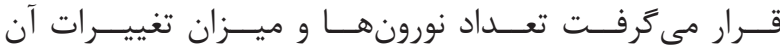

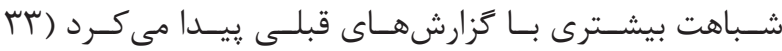

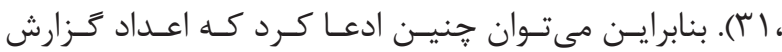

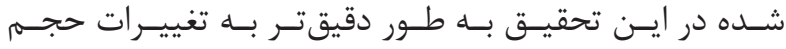

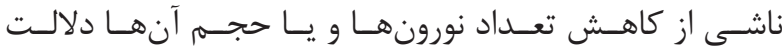

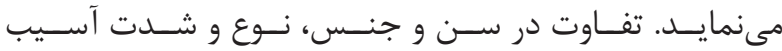

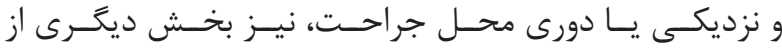

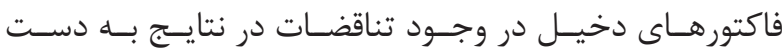

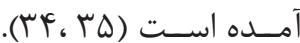

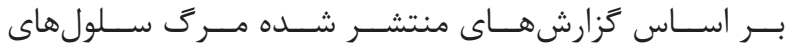

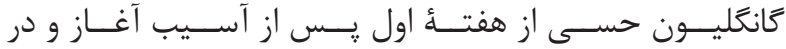

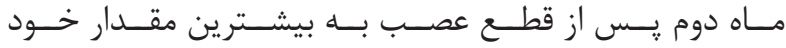

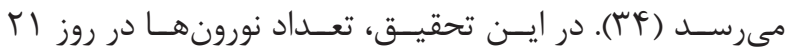

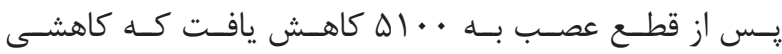

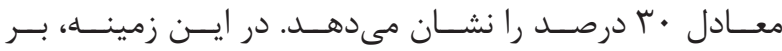

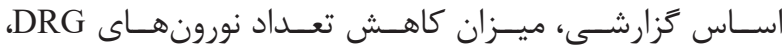

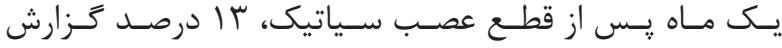

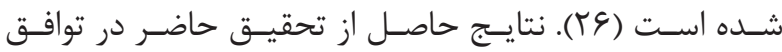

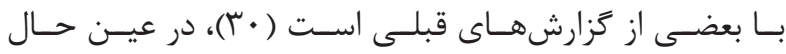

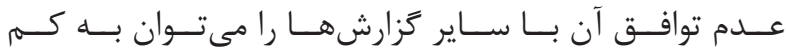

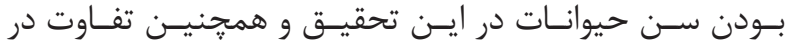

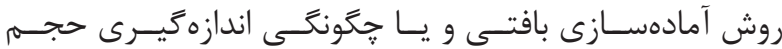

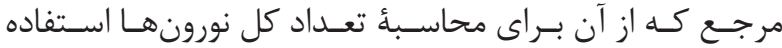

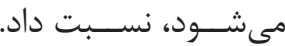

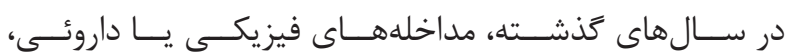

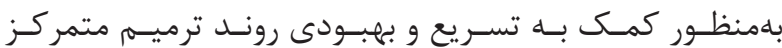

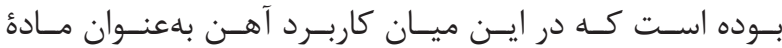

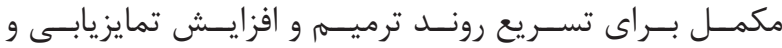

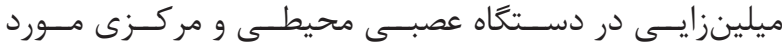

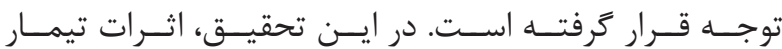

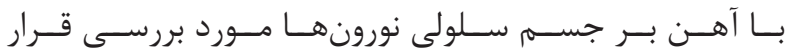

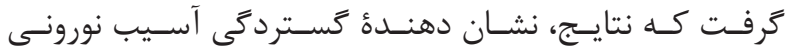

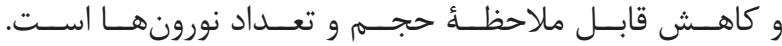

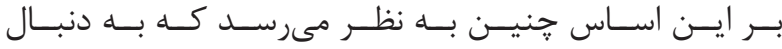

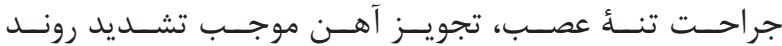

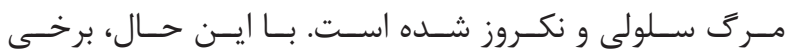

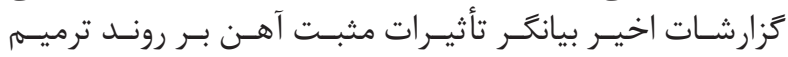

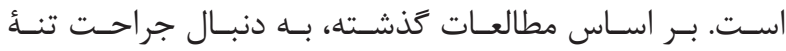

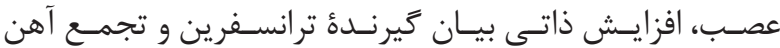

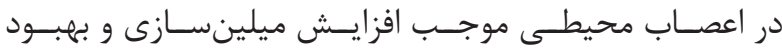

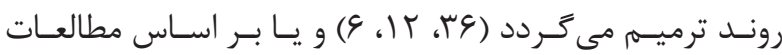

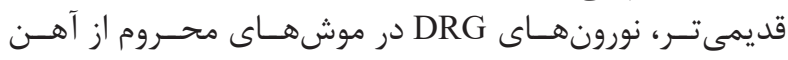

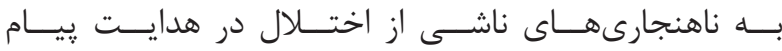

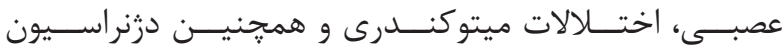

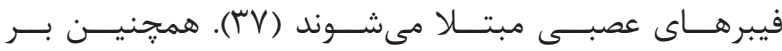

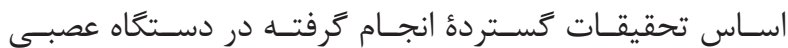

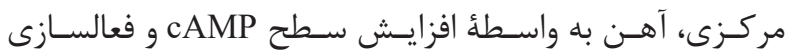

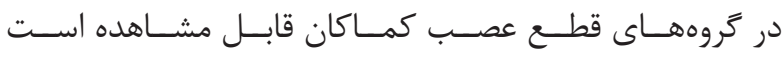

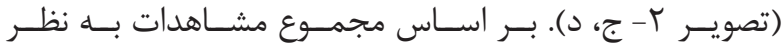

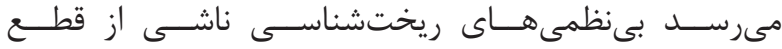

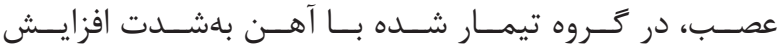

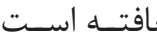

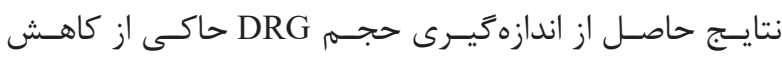

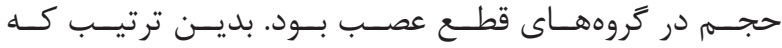

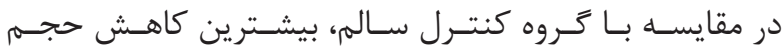

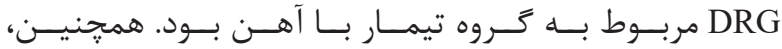

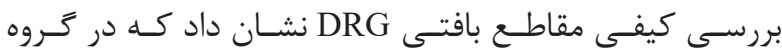

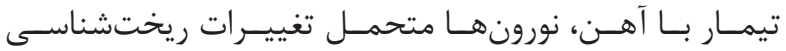

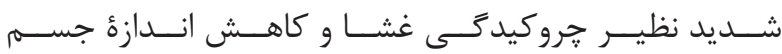

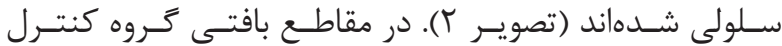

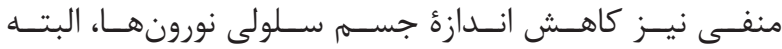

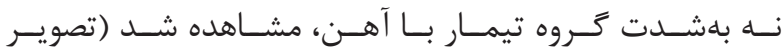

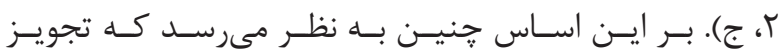

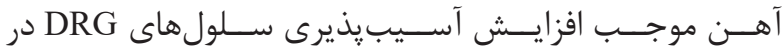

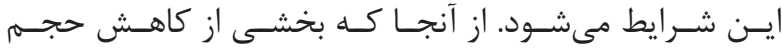

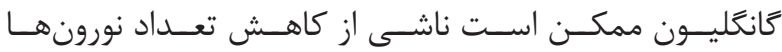

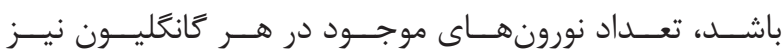

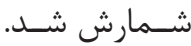

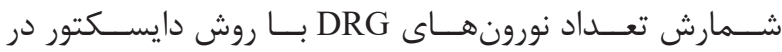

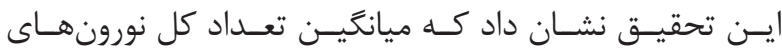

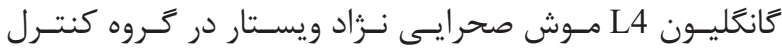

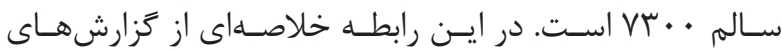

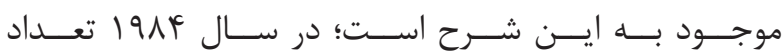

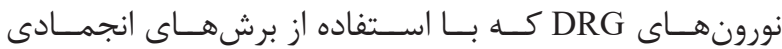

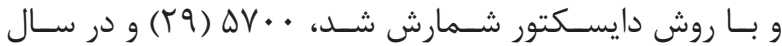

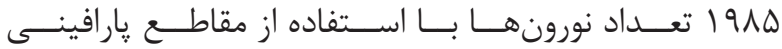

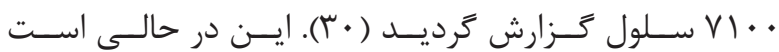

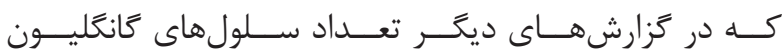

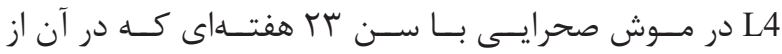

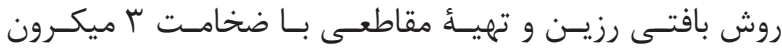

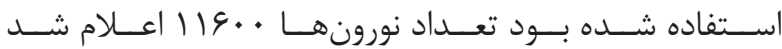

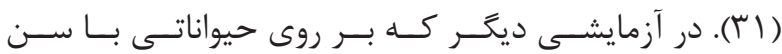

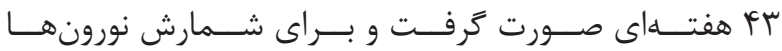

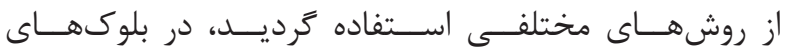

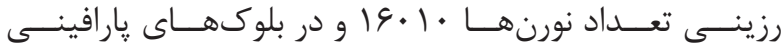

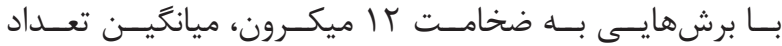

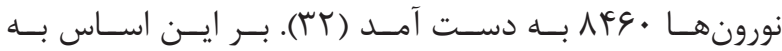

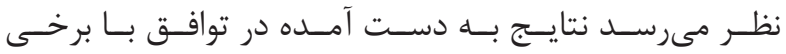

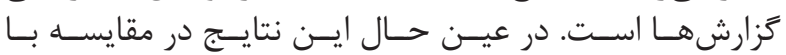

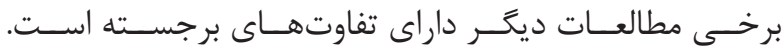

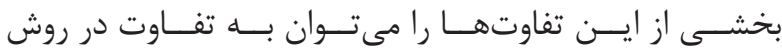

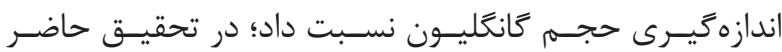

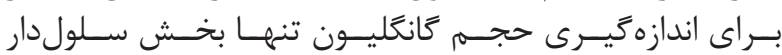

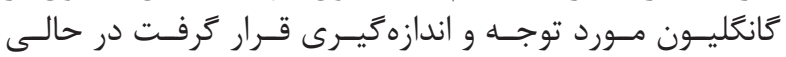

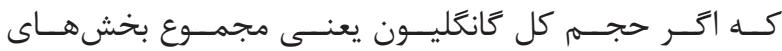




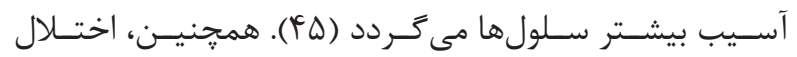

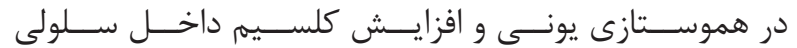

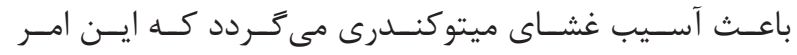

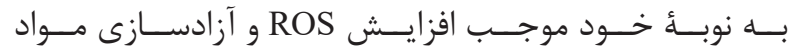

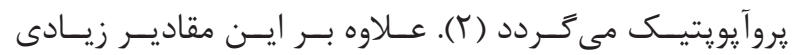

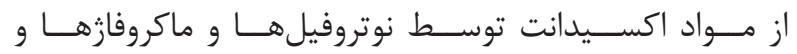

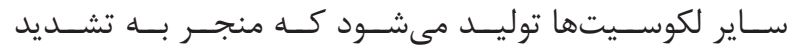

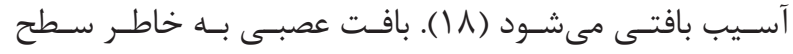

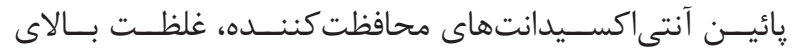

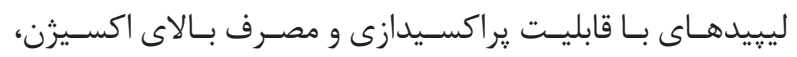

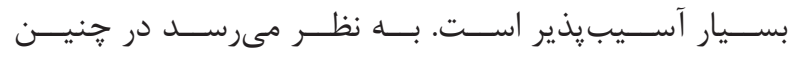

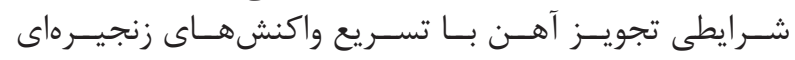

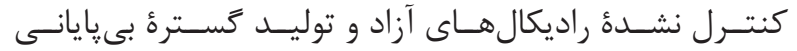

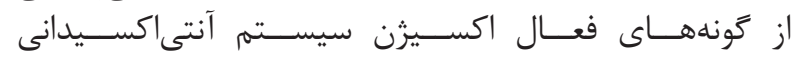

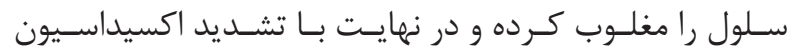

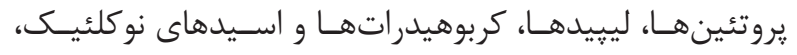

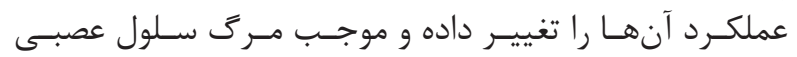

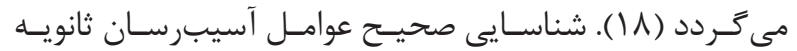

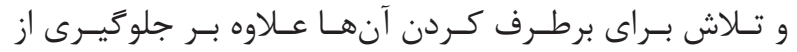

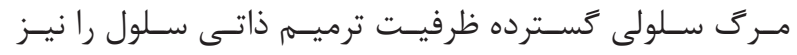

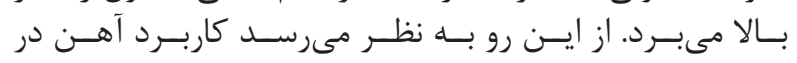

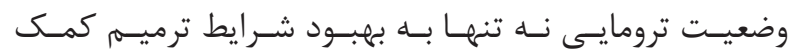

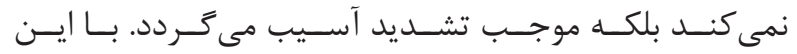

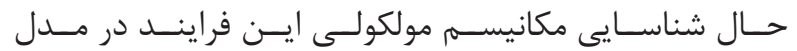

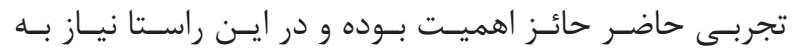

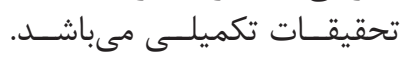

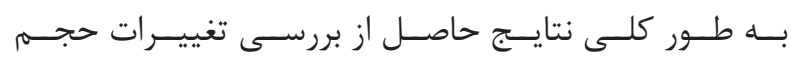

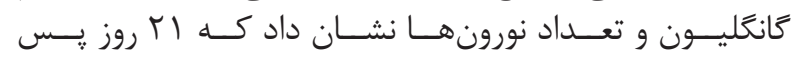

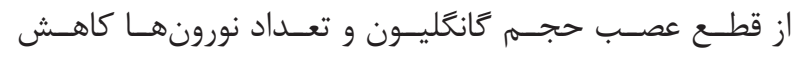

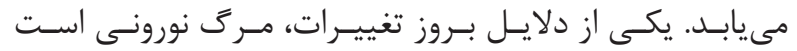

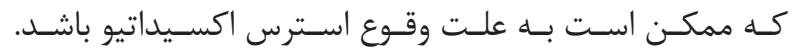

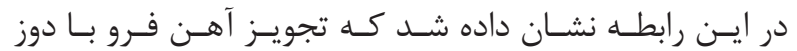

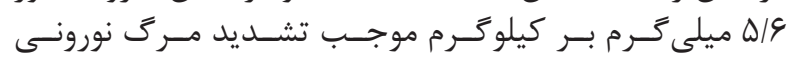

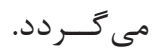

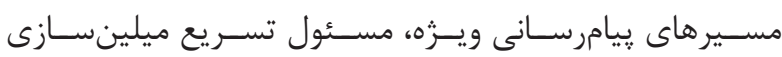

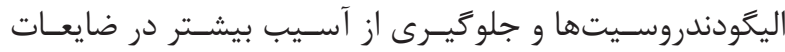

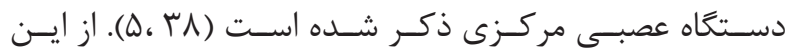

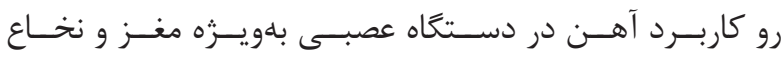

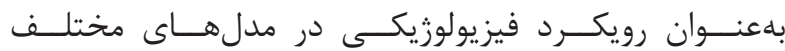
تجربسى مطـرح اسـتـ رونس

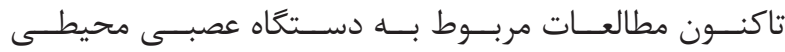

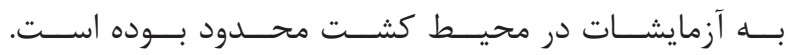

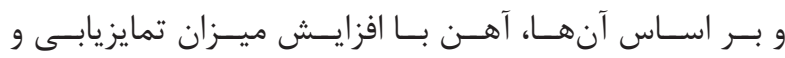

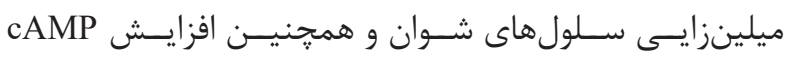

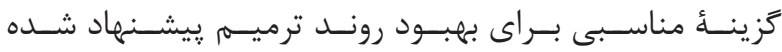

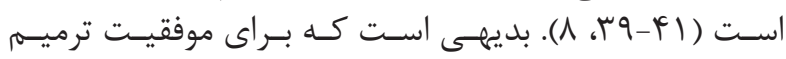

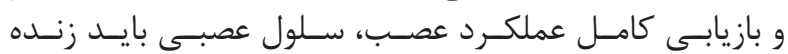

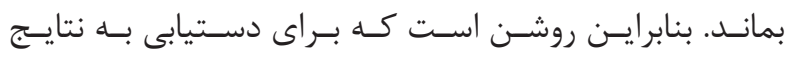

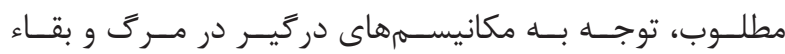

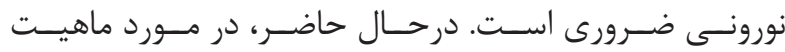

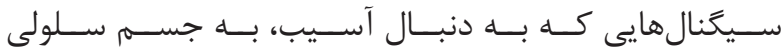

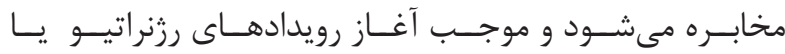

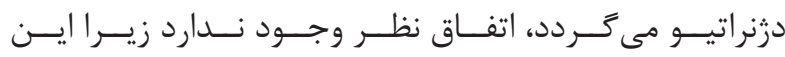

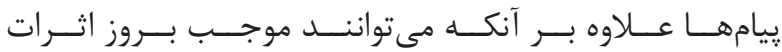

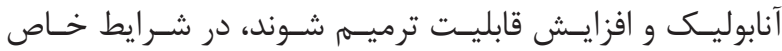

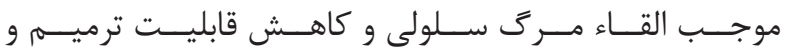

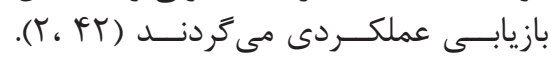

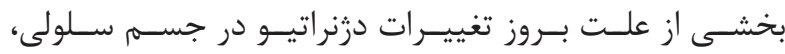

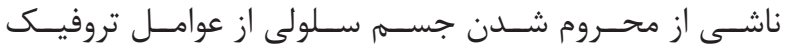

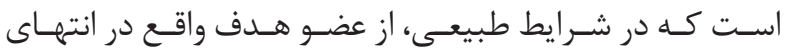

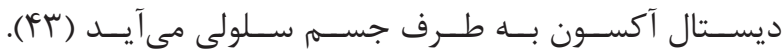

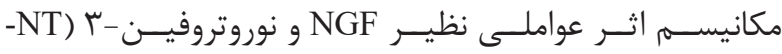

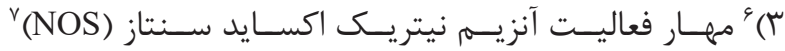

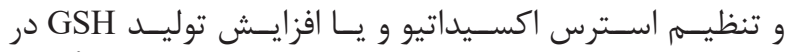

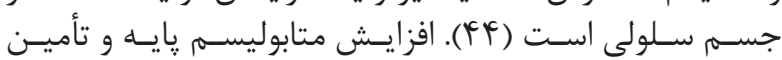

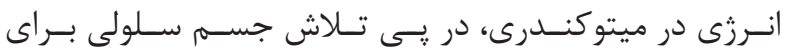

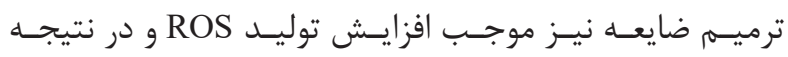


1 .Rotshenker S. Wallerian degeneration: the innateimmune response to traumatic nerve injury. J Neuroinflammation. 2011; 8(1): 109. doi: 10.1186/17422094-8-109.

2. Terenghi G, Hart A, Wiberg M. The nerve injury and the dying neurons: diagnosis and prevention. J Hand Surg Eur Vol. 2011; 36(9): 730-4.

3. Raivich G, Makwana M. The making of successful axonal regeneration: genes, molecules and signal transduction pathways. Brain Res Rev. 2007; 53(2): 287-311.

4. Goldstein EZ, Church JS, Hesp ZC, Popovich PG, McTigue DM. A silver lining of neuroinflammation: beneficial effects of myelination. Exp Neurol. 2016; 283: $550-9$.

5. Todorich B, Pasquini JM, Garcia CI, Paez PM, Connor JR. Oligodendrocytes and myelination: the role of iron. Glia. 2009; 57(5): 467-78.

6. Hung HA, Sun G, Keles S, Svaren J. Dynamic regulation of Schwann cell enhancers after peripheral nerve injury. J Biol Chem. 2015; 290(11): 6937-50.

7. Laskey J, Webb I, Schulman HM, Ponka P. Evidence that transferrin supports cell proliferation by supplying iron for DNA synthesis. Exp Cell Res. 1988; 176(1): $87-95$.

8. Salis C, Davio C, Usach V, Urtasun N, Goitia B, Martinez-Vivot $\mathrm{R}$, et al. Iron and holotransferrin induce cAMP-dependent differentiation of Schwann cells. Neurochem Int. 2012; 61(5): 798-806.

9. Martinez-Vivot R, Copello G, Leal C, Piñero G, Usach V, Rozenszajn M, et al. DMT1 iron uptake in the PNS: bridging the gap between injury and regeneration. Metallomics. 2015; 7(10): 1381-9.

10. Baum P, Kosacka J, Estrela-Lopis I, Woidt K, Serke $\mathrm{H}$, Paeschke S, et al. The role of nerve inflammation and exogenous iron load in experimental peripheral diabetic neuropathy (PDN). Metabolism. 2016; 65(4): 391-405.

11 .Rosato-Siri MV, Marziali L, Guitart ME, Badaracco ME, Puntel M, Pitossi F, et al. Iron availability compromises not only oligodendrocytes but also astrocytes and microglial cells. Mol Neurobiol. 2018; 55(2): 1068-81.

12. Raivich G, Graeber M, Gehrmann J, Kreutzberg G. Transferrin receptor expression and iron uptake in the injured and regenerating rat sciatic nerve. Eur $\mathrm{J}$
Neurosci. 1991; 3(10): 919-27.

13. Ziv-Polat O, Shahar A, Levy I, Skaat H, Neuman S, Fregnan F, et al. The role of neurotrophic factors conjugated to iron oxide nanoparticles in peripheral nerve regeneration: in vitro studies. Biomed Res Int. 2014; 2014. doi: 10.1155/2014/267808.

14. Batista-Nascimento L, Pimentel C, Andrade Menezes $\mathrm{R}$, Rodrigues-Pousada C. Iron and neurodegeneration: from cellular homeostasis to disease. Oxid Med Cell Longev. 2012; 2012. doi: 10.1155/2012/128647.

15. Poh Loh K, Hong Huang S, De Silva R, Tan H, Benny $\mathrm{K}$, Zhun Zhu Y. Oxidative stress: apoptosis in neuronal injury. Curr Alzheimer Res. 2006; 3(4): 327-37.

16. Núñez MT, Urrutia P, Mena N, Aguirre P, Tapia V, Salazar J. Iron toxicity in neurodegeneration. Biometals. 2012; 25(4): 761-76.

17 .Dixon SJ, Stockwell BR. The role of iron and reactive oxygen species in cell death. Nat Chem Biol. 2014; 10(1): 9-17.

18. Bains M, Hall ED. Antioxidant therapies in traumatic brain and spinal cord injury. Biochim Biophys Acta. 2012; 1822(5): 675-84.

19 .Gozzelino R, Arosio P. The importance of iron in pathophysiologic conditions. Front Pharmacol. 2015; 6: 26. doi: 10.3389/fphar.2015.00026.

20. Levi S, Taveggia C. Iron homeostasis in peripheral nervous system, still a black box? Antioxid Redox Signal. 2014; 21(4): 634-48.

21. Aldrich RA. Acute iron toxicity. Iron in Clinical Medicine. 1958: 93.

22. Schwertmann U, Cornell RM. Iron oxides in the laboratory: preparation and characterization: John Wiley \& Sons; 2008.

23. Ali YF, Desouky OS, Selim NS, Ereiba KM. Assessment of the role of $\alpha$-lipoic acid against the oxidative stress of induced iron overload. J Radiat Res Appl Sci. 2015; 8(1): 26-35.

24. Gundersen H, Bagger P, Bendtsen T, Evans S, Korbo L, Marcussen N, et al. The new stereological tools: disector, fractionator, nucleator and point sampled intercepts and their use in pathological research and diagnosis. Apmis. 1988; 96(7-12): 857-81.

25. Snell RS. Clinical neuroanatomy: Lippincott 
Williams \& Wilkins; 2010.

26. Groves MJ, Christopherson T, Giometto B, Scaravilli F. Axotomy-induced apoptosis in adult rat primary sensory neurons. J Neurocytol. 1997; 26(9): 615-24.

27. Atlasi MA, Mehdizadeh M, Bahadori MH, Joghataei MT. Morphological identification of cell death in dorsal root ganglion neurons following peripheral nerve injury and repair in adult rat. Iran Biomed J. 2009; 13(2): 65-72.

28 .Hart AM, Brannstrom T, Wiberg M, Terenghi G. Primary sensory neurons and satellite cells after peripheral axotomy in the adult rat. Exp Brain Res. 2002; 142(3): 308-18.

29. Bondok AA, Sansone FM. Retrograde and transganglionic degeneration of sensory neurons after a peripheral nerve lesion at birth. Exp Neurol. 1984; 86(2): 322-30.

30 .Devor M, Govrin-Lippmann R, Frank L, Raber P. Proliferation of primary sensory neurons in adult rat dorsal root ganglion and the kinetics of retrograde cell loss after sciatic nerve section. Somatosens Res. 1985; 3(2): $139-67$.

31. Schmalbruch H. Loss of sensory neurons after sciatic nerve section in the rat. Anat Rec. 1987; 219(3): 323-9.

32. Schmalbruch $H$. The number of neurons in dorsal root ganglia L4-L6 of the rat. Anat Rec. 1987; 219(3): 315-22.

33. Tandrup T. A method for unbiased and efficient estimation of number and mean volume of specified neuron subtypes in rat dorsal root ganglion. J Comp Neurol. 1993; 329(2): 269-76.

34. Vestergaard S, Tandrup T, Jakobsen J. Effect of permanent axotomy on number and volume of dorsal root ganglion cell bodies. J Comp Neurol. 1997; 388(2): 307-12.

35 .Ygge J. Neuronal loss in lumbar dorsal root ganglia after proximal compared to distal sciatic nerve resection: a quantitative study in the rat. Brain Res. 1989; 478(1):
193-5.

36. Graeber M, Raivich G, Kreutzberg G. Increase of transferrin receptors and iron uptake in regenerating motor neurons. J Neurosci Res. 1989; 23(3): 342-5.

37. Finch $\mathrm{C}$, Miller L, Inamdar A, Person R, Seiler K, Mackler B. Iron deficiency in the rat. Physiological and biochemical studies of muscle dysfunction. J Clin Invest. 1976; 58(2): 447-53.

38. Connor JR, Menzies SL. Relationship of iron to oligondendrocytes and myelination. Glia. 1996; 17(2): 83-93.

39. Salis C, Goedelmann C, Pasquini J, Soto E, SettonAvruj C. Holotransferrin but not apotransferrin prevents schwann cell de-differentiation in culture. Dev Neurosci. 2002; 24(2-3): 214-21.

40. Salis C, Setton C, Soto E, Pasquini J. The mRNA of transferrin is expressed in Schwann cells during their maturation and after nerve injury. Exp Neurol. 2007; 207(1): 85-94.

41. Vivot RM, Goitia B, Usach V, Setton-Avruj PC. DMT1 as a candidate for non-transferrin-bound iron uptake in the peripheral nervous system. Biofactors. 2013; 39(4): 476-84.

42. Donaldson K, Höke A. Studying axonal degeneration and regeneration using in vitro and in vivo models: the translational potential. Future Neurology. 2014; 9(4): 461-73.

43. Bastien D, Lacroix S. Cytokine pathways regulating glial and leukocyte function after spinal cord and peripheral nerve injury. Exp Neurol. 2014; 258: 62-77.

44. Jackson GR, Apffel L, Werrbach-Perez K, Perez-Polo JR. Role of nerve growth factor in oxidant-antioxidant balance and neuronal injury. I. Stimulation of hydrogen peroxide resistance. J Neurosci Res. 1990; 25(3): 360-8.

45. Al-Abdulla NA, Martin LJ. Apoptosis of retrogradely degenerating neurons occurs in association with the accumulation of perikaryal mitochondria and oxidative damage to the nucleus. Am J Pathol. 1998; 153(2): 447-56. 